\title{
Extra Anatomical Bypass for Common Femoral Artery Pseudoaneurysm following Resuscitative Endovascular Balloon Occlusion of the Aorta (REBOA)
}

\author{
HJ Krüger MBChB DipPEC(SA) ${ }^{1}$, JH Couch MBChB MRCS ${ }^{2}$ and \\ GV Oosthuizen MBChB LMCC FCS(SA) FACS ${ }^{2,3}$ \\ Division of Surgery, Faculty of Medicine and Health Sciences, University of Stellenbosch, South Africa \\ ${ }^{2}$ Ngwelezana Tertiary Hospital, Empangeni, South Africa \\ 'Division of Surgery, Faculty of Health Sciences, University of KwaZulu-Natal, South Africa
}

\begin{abstract}
Background: Improvements in the instrumentation and guidelines for the use of Resuscitative Endovascular Balloon Occlusion of the Aorta (REBOA) have increased its use as an adjunct in managing haemorrhagic shock. REBOArelated complications continue to be assessed and described.

Methods: We describe a case of a femoral artery pseudoaneurysm within an infected groin wound after REBOA usage in a 25 -year-old male after several bouts of sepsis and complications related to the initial penetrating injury and associated stay in the intensive care unit.

Results: An extra-anatomical external iliac-to-superficial femoral artery bypass was performed using a 6-mm polytetrafluoroethylene graft to treat the femoral artery pseudoaneurysm successfully.

Conclusion: REBOA is a well-described adjunct in the management of haemorrhagic shock. The immediate and delayed complications should be not overlooked. Deviations from the expected post-operative course should be promptly recognised and managed by a clinician with appropriate expertise.
\end{abstract}

Keywords: REBOA; Pseudoaneurysm; REBOA Complications

\section{INTRODUCTION}

Femoral artery pseudoaneurysm (FAP) is a well-known complication of common femoral artery (CFA) cannulation for diagnostic and interventional procedures, with rates of $0.05-2 \%$ for diagnostic [1] and up to $10 \%$ for interventional [2] procedures. Iatrogenic FAPs have been reported in the American Association for the

\section{Corresponding author:}

Henk Kruger, Division of Surgery, Faculty of Medicine and Health Sciences, University of Stellenbosch, South Africa. Email: henk.kruger90@gmail.com

(c) 2021 CC BY-NC 4.0 - in cooperation with Depts. of Cardiothoracic/Vascular Surgery, General Surgery and Anesthesia, Örebro University Hospital and Örebro University, Sweden
Surgery of Trauma (AAST) prospective Aortic Occlusion for Resuscitation in Acute Care and Trauma Surgery (AORTA) registry, with one in a case series of 46 patients $(2.1 \%)$ [3]. There are multiple treatment options for iatrogenic FAP, including ultrasound compression, thrombin injection, primary repair, endovascular stents and bypass procedures [4]. We present a patient who developed FAP following Resuscitative Endovascular Balloon Occlusion of the Aorta (REBOA), which necessitated an extra-anatomical bypass.

\section{CASE PRESENTATION}

A 25-year-old male with no comorbidities presented to a regional hospital in rural South Africa after being stabbed inferior to his umbilicus. On arrival, the patient was haemodynamically stable, with a single penetrating 
wound to his anterior abdominal wall and peritonitis. Standard Advanced Trauma Life Support (ATLS) protocols were followed, and the patient was taken to theatre for laparotomy. At laparotomy, an AAST grade-2 smallbowel injury was noted $50 \mathrm{~cm}$ from the duodeno-jejunal flexure, with a non-expanding central haematoma extending above the coeliac trunk. Intra-operatively, the patient became haemodynamically unstable and required resuscitation with blood products.

The small-bowel injury was stapled off, a size 7-F introducer was placed in the right CFA simultaneously, and a Rescue Balloon-ER ${ }^{\circledR}$ (Tokai Medical Products, Aichi, Japan) was placed over a guidewire into Zone 1 with tactile confirmation of the level of balloon placement, while a senior surgeon was called to assist with the procedure. The aorta and inferior vena cava were exposed using Cattel-Braasch and Mattox manoeuvres. An 8-mm puncture wound was noted on the intrarenal anterior aorta, and digital control was obtained. The REBOA catheter was retracted proximal to the injury using tactile confirmation of positioning, allowing flow into the superior mesenteric artery but not the renal arteries; this was confirmed by a palpable superior mesenteric arterial pulse. Partial REBOA was employed with proximal systolic blood pressure kept above $90 \mathrm{mmHg}$, while distal diastolic pressures remained above $35 \mathrm{mmHg}$ during the procedure. Total time for REBOA placement was $40 \mathrm{~min}$, during which the aortic injury was primarily repaired. At the end of the procedure, the patient was coagulopathic and an open repair of the right CFA was necessitated after sheath removal.

The patient was transferred to the intensive care unit (ICU) for physiological restoration. At re-look laparotomy $48 \mathrm{~h}$ later, a primary anastomosis of the smallbowel injury and definitive closure were performed.

Post-operatively, the patient developed a ventilator-associated pneumonia that resulted in a prolonged ICU stay. He also developed acute kidney injury that required haemodialysis but subsequently recovered. The patient was transferred to the ward 2 weeks after initial laparotomy; 1 week later, he developed signs of sepsis. A computed tomography (CT) scan revealed intra-abdominal collections. A re-look laparotomy was performed and a leak from the site of the small-bowel anastomosis noted, which was managed by performing a Bishop-Koop procedure [5]. The patient was treated with total parenteral nutrition and antibiotics, with subsequent clinical improvement.

At 28 days post-operatively, a pulsatile mass in the right groin was noted over the site of the previous CFA repair, with obvious superficial wound sepsis evident. A CT angiogram confirmed a right CFA pseudoaneurysm of $4.5 \mathrm{~cm}$, with compression of the femoral vein. The patient was taken to the operating room, at which time the aneurysm ruptured freely and required digital control. The patient underwent extra-anatomical bypass from the right external iliac artery to the right superficial femoral artery. Because the saphenous vein was of insufficient calibre, a 6-mm polytetrafluoroethylene (PTFE) graft was used. Peri-operatively, prophylactic antibiotics were administered and extensive washout of the surgical bed with saline and iodine-containing solutions was performed. Post-operatively the patient was placed on intravenous antibiotics for 2 weeks to mitigate graft sepsis. Diligent wound care was also performed on the ward. The patient was anticoagulated with enoxaparin, post-operatively, as per local guidelines. The patient recovered with no evidence of further arterial complications. He was discharged home with negligible output from the Bishop-Koop jejunostomy and was scheduled for elective stoma closure at a later date.

\section{Ethical Approval and Informed Consent}

Ethical approval to report these cases was given by University of KwaZulu-Natal Bioethics Research Committee (BCA027/19).

\section{DISCUSSION}

REBOA use in trauma patients and others is a welldescribed technique to assist in managing, and in some cases preventing, potential catastrophic bleeding $[6,7]$. As indications for the use of REBOA in the management of life-threatening haemorrhage grow and its popularity amongst clinicians increases, more complications can be expected. Complications related to the usage of REBOA can be divided into the various phases of REBOA, as described by Davidson et al. [8] (Table 1).

Limb ischaemia related to sheath placement has been well described, with rates varying between $0 \%$ [3] and $3.6 \%$ [9]. The initial use of REBOA employed larger sheath sizes $(10-14 \mathrm{~F})$; however, downscaling to smaller sizes of catheters $(7 \mathrm{~F})$ has resulted in a decrease of limb ischaemia post-REBOA [2,10,11]. The use of ultrasound-guided puncture has also resulted in a decrease in local complications, as a higher success rate in CFA cannulation is associated with the use of ultrasound [12].

The difference in incidence of FAP between interventional and diagnostic procedures is reported to be related to the size of the sheath used during both procedures, with interventional cannulation requiring larger sizes. Local factors such as sepsis (specifically Staphylococcus aureus sepsis) and patient factors (older age, obesity, female gender, renal replacement therapy) [13], as well as technical factors such as multiple punctures, coagulopathy (iatrogenic) and site of puncture below the CFA increase the risk of formation of pseudoaneurysms [14]. Of these factors, local sepsis over the site of the repair is thought to be the biggest contributor to the development of FAP in our patient, although renal replacement therapy, systemic sepsis and the initial coagulopathy may have also contributed to the formation of FAP. 
Table 1 Potential complications and challenges associated with each step of REBOA. Reproduced with permission from Davidson AJ, Russo RM, Reva VA, et al. The pitfalls of resuscitative endovascular balloon occlusion of the aorta: risk factors and mitigation strategies. J Trauma Acute Care Surg. 2018;84:192-202 [8].

\begin{tabular}{|c|c|c|}
\hline Step & Potential Complication & Challenges \\
\hline \multirow[t]{8}{*}{ Arterial access } & Inability to obtain access & Body habitus \\
\hline & Bleeding & Hypotension \\
\hline & Improper location of arterial puncture & Hypoxia \\
\hline & Venous access & Vasospasm \\
\hline & & Variant anatomy \\
\hline & & Calcified lesions \\
\hline & & Inexperience \\
\hline & & Junctional injury \\
\hline \multirow[t]{3}{*}{ Balloon positioning } & Wrong anatomical location & Arterial injury \\
\hline & Inability to pass catheter & Misalignment of arterial access \\
\hline & & Preexisting vascular pathology \\
\hline \multirow[t]{4}{*}{ Balloon inflation } & Arterial injury/rupture & Requires tactile feedback \\
\hline & Balloon rupture & Balloon burst pressure \\
\hline & Unintended ischemia & Balloon misalignment \\
\hline & Exacerbation of proximal injuries & Undiagnosed proximal injury \\
\hline \multirow[t]{4}{*}{ Management during balloon occlusion } & Balloon migration/prolapse & Duration of occlusion \\
\hline & Increasing ischemic burden & Active resuscitation \\
\hline & Supraphysiologic proximal pressures & Increasing proximal pressure \\
\hline & Thrombosis of access site & $\begin{array}{l}\text { Arterial occlusion due to sheath } \\
\text { Distal ischemia }\end{array}$ \\
\hline \multirow[t]{4}{*}{ Balloon deflation } & Cardiovascular collapse/hypotension & Ischemia-reperfusion injury \\
\hline & Clot disruption with ongoing haemorrhage & Coordination of resuscitation \\
\hline & Hyperkalemia & Rapid/unpredictable return of distal flow \\
\hline & Acidosis & \\
\hline \multirow{3}{*}{$\begin{array}{l}\text { Sheath removal and postoperative } \\
\text { management }\end{array}$} & Hematoma or pseudoaneurysm & Access site vascular injury \\
\hline & Thromboembolism & Vasospasm \\
\hline & Arterial dissection Limb loss/amputation & Additional procedure(s) required \\
\hline
\end{tabular}

The Creative Commons license does not apply to this content. Use of the material in any format is prohibited without written permission from the publisher, Wolters Kluwer Health, Inc. Please contact permissions@/ww.com for further information.

In patients who underwent cannulation of the CFA for cardiac catherization, $94 \%$ of FAP appeared before 7 days post-puncture, with $98.3 \%$ presenting with a groin mass [14]. However, patients with large FAP requiring surgery presented only $1-4$ weeks after arterial puncture [15], while cases of delayed presentation of FAP have been reported up to 5 months after [16].

Routine screening of all patients with duplex doppler 1 day post-CFA cannulation for diagnostic procedures revealed an incidence of $2.75 \%$ [17], which was similar to studies that relied only on clinical symptoms to diagnose patients with FAP [14]. This suggests that no routine radiological surveillance is required following arterial cannulation.

In our facility, we perform regular clinical examinations (twice daily while in ICU) of the groin after REBOA placement, and clinical findings suggestive of FAP are followed up with CT angiography to confirm the presence and extent of the FAP. Treatment options for FAP are based on size and symptoms and time of diagnosis [18]. Pseudoaneurysms smaller than 2-3 cm may close spontaneously or with ultrasound compression [4,18]. Other treatment options are injection of local sclerosing agents, coiling and endovascular stent placement, each based on the individual characteristics of the FAP, technical resources, and skills available $[4,19]$. Surgery is reserved for patients in centres where the aforementioned modalities are not available and when pressure symptoms are present, distal ischaemia is noted, a "wide" aneurysmal neck is noted on ultrasound, enlargement of the aneurysm exists, infection is present, and other therapies have failed $[1,15]$. Surgical options for managing FAP are ligation, primary repair, vein patch angioplasty, resection and reverse interposition vein graft, synthetic graft or extra-anatomical bypass in the case of sepsis [15,20,21].

In our centre, we do not have access to endovascular facilities, and thus an open repair was performed for this patient. Emergency repair was necessary because of rupture and profuse bleeding. With local sepsis present, an interposition graft was not deemed feasible and, therefore, we opted for extra-anatomical bypass. Because of insufficient calibre of the saphenous vein, a PFTE graft was placed. This highlights the importance of having surgeons on board who are trained in vascular techniques at those centres with no endovascular facilities, when REBOA is employed. 


\section{CONCLUSION}

Patients who undergo REBOA often have multiple complex injuries, such as in the case we have described. Although the risk has lessened with the use of smaller sheaths, the expected coagulopathy, renal failure, hospitalacquired sepsis and underlying patient factors place such patients at risk for FAP development. This is the first case that we are aware of that necessitated extra-anatomical bypass for treatment of FAP after REBOA and serves as a reminder that REBOA is not without complication.

\section{Ethics Statement}

(1) All the authors mentioned in the manuscript have agreed to authorship, read and approved the manuscript, and given consent for submission and subsequent publication of the manuscript.

(2) The authors declare that they have read and abided by the JEVTM statement of ethical standards including rules of informed consent and ethical committee approval as stated in the article. Ethical approval was obtained from University of KwaZuluNatal Bioethics Research Committee (BCA027/19).

\section{Conflicts of Interest}

The authors declare that they have no conflicts of interest.

\section{Funding}

The authors received no financial support for the research, authorship, and/or publication of this article.

\section{REFERENCES}

[1] Webber GW, Jang J, Gustavson S, Olin JW. Contemporary management of postcatheterization pseudoaneurysms. Circulation. 2007;115(20):2666-74.

[2] Teeter WA, Matsumoto J, Idoguchi K, et al. Smaller introducer sheaths for REBOA may be associated with fewer complications. J Trauma Acute Care Surg. 2016;81(6):1039-44.

[3] Du Bose JJ, Scalea TM, Brenner M, et al. The AAST prospective Aortic Occlusion for Resuscitation in Trauma and Acute Care Surgery (AORTA) registry: data on contemporary utilization and outcomes of aortic occlusion and resuscitative balloon occlusion of the aorta (REBOA). J Trauma Acute Care Surg. 2016;81: 409-19

[4] Tisi PV, Callam MJ. Treatment for femoral pseudoaneurysms. Cochrane Database Syst Rev.2009;(2):CD004981. doi: 10.1002/14651858.CD004981.pub3. Update in: Cochrane Database Syst Rev. 2013;11:CD004981.

[5] Dickson-Lowe RA, Pienaar Z, Buitendag JJP, Oosthuizen G. Bishop-Koop jejunostomy in an adult following proximal small bowel anastomotic breakdown. BMJ Case Rep. 2018;11(1):10-2.

[6] Theodorou CM, Salcedo ES, Dubose JJ, Galante JM. Hate to burst your balloon: successful reboa use takes more than a course. J Endovasc Resusc Trauma Manag. 2020;4(1):21-9.

[7] Whittington JR, Pagan ME, Nevil BD, et al. Risk of vascular complications in prophylactic compared to emergent resuscitative endovascular balloon occlusion of the aorta (REBOA) in the management of placenta accreta spectrum. J Matern Neonatal Med. 2020; 1-4. doi: https://doi.org/10.1080/14767058.2020.1802717. Epub ahead of print.

[8] Davidson AJ, Russo RM, Reva VA, et al. The pitfalls of resuscitative endovascular balloon occlusion of the aorta: risk factors and mitigation strategies. J Trauma Acute Care Surg. 2018;84:192-202

[9] Joseph B, Zeeshan M, Sakran JV, et al. Nationwide analysis of resuscitative endovascular balloon occlusion of the aorta in civilian trauma. JAMA Surg. 2019; 154(6):500-8.

[10] Kim S, Chung JS, Jang SW, Jung PY. Pitfalls, complications, and necessity of education about REBOA: a single regional trauma center study. J Trauma Inj. 2020;33(3):153-61.

[11] Osborn LA, Brenner ML, Prater SJ, Moore LJ. Resuscitative endovascular balloon occlusion of the aorta: current evidence. Open Access Emerg Med. 2019;11:29-38.

[12] Long B, Hafen L, Koyfman A, Gottlieb M. Resuscitative endovascular balloon occlusion of the aorta: a review for emergency clinicians. J Emerg Med.2019;56(6):687-97. doi: https://doi.org/10.1016/j.jemermed.2019.03.030

[13] Renner J, Pasquier P, Falzone E, Rozwadowski F, Mérat S. Life-threatening rupture of a false aneurysm after femoral arterial catheterization: unexpected delay after a common procedure. Case Rep Vasc Med. 2013;2013:1-3.

[14] Kassem HH, Elmahdy MF, Ewis EB, Mahdy SG. Incidence and predictors of post-catheterization femoral artery pseudoaneurysms. Egypt Heart J. 2013;65(3): 213-21. doi: http://dx.doi.org/10.1016/j.ehj.2012.07.003.

[15] Mousa A, S Al Mulhim AR, Audeh A, Ghadeer B Al, Khaldi F Al. Surgical treatment strategies of iatrogenic giant femoral artery pseudoaneurysms. J Vasc Endovasc Surg. 2017;2(1):1-5.

[16] Korabathina R, Eckstein D, Coppola JT. Delayed occurrence of radial artery pseudoaneurysm following transradial percutaneous coronary intervention. J Cardiol Cases. 2015;11(4):117-9. doi: http://dx.doi.org/10.1016/ j.jccase.2014.12.003.

[17] Eleshra A, Kim D, Park HS, Lee T. Access site pseudoaneurysms after endovascular intervention for peripheral arterial diseases. Ann Surg Treat Res. 2019;96(6):305-12.

[18] Rivera PA, Dattilo JB. Pseudoaneurysm. Treasure Island (FL): StatPearls Publishing, 2020. Available from: https://www.ncbi.nlm.nih.gov/books/NBK542244/.

[19] Dalvin M, Dessecker B, Vitvitsky E. Treatment of common femoral artery pseudoaneurysm: a novel approach utilizing a VASCADE percutaneous closure device. Case Rep Surg. 2019;2019:1397981. doi: 10.1155/2019/1397981.

[20] Alhaieg OM, Saleh MS, Hussein M, et al. Femoral artery pseudoaneurysm. Al-Azhar Assiut Medical J.2014;12(4): 246-62.

[21] Psathas E, Lioudaki S, Karantonis F-F, Charalampoudis P, Papadopoulos O, Klonaris C. Management of a complicated ruptured infected pseudoaneurysm of the femoral artery in a drug addict. Case Rep Vasc Med. 2012; 2012:1-4. 